\title{
High rates of community-acquired, Panton-Valentine LEUKOCIDIN (PVL)- POSITIVE METHICILLIN-RESISTANT $S$. aUREUS (MRSA) INFECTIONS IN ADULT OUtPatients IN GREECE
}

\author{
S Vourli ${ }^{1}$, H Vagiakou², G Ganteris ${ }^{2}$, M Orfanidou², M Polemis ${ }^{1}$, A Vatopoulos (avatopou@nsph.gr) ${ }^{1}$, H Malamou-Ladas ${ }^{2}$ \\ 1. Department of Microbiology., National School of Public Health, Athens, Greece \\ 2. Department of Microbiology, “G Gennimatas” General Hospital, Athens, Greece
}

Staphylococcus aureus was isolated in 88 (30. 8\%) of 286 adult patients suffering from various skin and soft-tissue infections examined in the outpatient department of a 650 bed tertiary-care hospital of Athens, Greece between January 2006 and December 2007. Twenty-seven (30.7\%) of the S. aureus infections were caused by methicillin-resistant $S$. aureus (MRSA). All MRSA isolates were also resistant to tetracycline, fucidic acid and kanamycin, but were sensitive to gentamicin and tobramycin, as well as to to cotrimoxazole, chloramphenicol, quinolones, clindamycin and erythromycin. All isolates belonged to staphylococcal cassette chromosome mec elements (SCCmec) type IV, and were found to carry the lukF-PV and lukS genes coding for Panton-Valentine leukocidin (PVL). Pulsed-field gel electrophoresis (PFGE) and spatyping revealed high genetic similarity among all MRSA isolates and with the PFGE pattern of the well-described ST80 clone that seems to be spreading through Europe. The high prevalence of MRSA among $S$. aureus infections in the community signify that empiric therapy in Greece, when clinically indicated, should exclude $\beta$-lactam antibiotics. Moreover, the establishment of an active screening for PVL-positive community-acquired (CA)-MRSA carriage and the adoption of a search and destroy strategy for CA-MRSA in all patients admitted with purulent skin and soft-tissue is of high priority in Greece as well as in all European countries which face high rates of CA-MRSA infection.

\section{Introduction}

Methicillin-resistant Staphylococcus aureus (MRSA) is a wellrecognised major cause of healthcare-associated infections. Over the past 10 years the epidemiology of this pathogen has changed throughout the world and infections caused by it have emerged in the community $[1,2]$. First reports of MRSA infections in the community were described predominantly in children without established risk factors for MRSA acquisition and were defined as community-acquired MRSA (CA-MRSA) [3]. Further infections have been reported among selected populations, including sports teams and correctional facility inmates. Moreover, infections in outpatients, mainly healthy, non-immunocompromised adults without risk factors have also been documented [1,2]. CA-MRSA isolates primarily cause skin and soft-tissue infections but serious, life-threatening, invasive infections such as bacteraemia and necrotizing pneumonia have also been described [4].
In Greece, 20 to $40 \%$ of all S. aureus skin and soft-tissue infections in paediatric outpatients are found to be due to CAMRSA $[5,6]$. In the presented study we investigated the prevalence of Panton-Valentine leucidine (PVL)-positive CA-MRSA among $S$. aureus infections in adult outpatients in a tertiary-care hospital of Athens.

\section{Materials and methods}

Between January 2006 and December 2007, 286 patients suffering from various skin and soft-tissue infections and with no history of hospitalization or any contact with a hospital during the past twelve months were examined in the outpatient department of a 650 bed tertiary-care hospital of Athens.

\section{Laboratory testing}

Microbiological examination of the respective clinical specimens and the identification of the species were performed by standard procedures. Resistance to oxacillin in S. aureus was assessed by the disc diffusion method, through cefoxitin resistance, according to the Clinical and Laboratory Standards Institute (CLSI) criteria [7]. The same criteria were used to determine resistance levels to other antibiotics (tetracycline, kanamycin, tobramycin, gentamicin, fucidic acid, chloramphenicol, erythromycin, ciprofloxacin and cotrimoxazol).

\section{Molecular testing}

Staphylococcal cassette chromosome elements (SCCmec) typing as well as detection of the mecA gene was performed by PCR, as described by Oliveira and de Lencastre [8]. The lukF-PV and lukS-PV genes coding for the PVL toxin, were detected by PCR, as described by Lina et al. [9]. To determine the genetic relatedness of the isolates, Smal restriction fragments of genomic DNA were separated by PFGE as described previously [10] and analysed by BioNumerics software, version 4.6 (Applied Maths, Sint-MartensLatem, Belgium), using Dice coefficients and the unweighted-pair group method by means of average linkages. Spa-typing was performed as described by Harmsen et al. [11] and spa types were determined using Ridom StaphType software version 1.4 (Ridom $\mathrm{GmbH}$, Würzburg, Germany). 


\section{Results}

S. aureus was isolated from 88 (30.8\%) of 286 patients presenting with skin infections without history of hospitalisation or any contact with a hospital during the last year. Upon sensitivity testing the infection was found to be caused by MRSA in 27 $(30.7 \%)$. Fourteen of the affected were men and 13 women. The mean age of these patients was 43 years, ranging from 29 to 56 years. Abscesses (skin abscesses 7, soft-tissue abscesses 9) dominated the clinical presentations, followed by furuncles (6), wound infections (4) and folliculitis (1) (Table). No statistically significant difference was found between the rates of methicillinsensitive $S$. aureus (MSSA) and MRSA isolated from the various types of skin and soft-tissue infections. Moreover, there was no difference in age or sex between patients suffering from MSSA or MRSA infections (data not shown).

All MRSA isolates were resistant to tetracycline, fucidic acid and kanamycin, but they were sensitive to tobramycin and gentamicin, as well as to cotrimoxazole, chloramphenicol, quinolones, clindamycin and erythromycin.

All isolates belonged to SCC mec type IV and carried the lukF-PV and IukS-PV genes. PFGE revealed high genetic similarity among all MRSA strains (Table). The PFGE patterns of 18 isolates were identical and shared $100 \%$ similarity with the PFGE pattern of the well-described ST80 clone that seems to be spreading through Europe $[12,13]$. The remaining nine isolates revealed differences in one to three bands and were allocated into four subpatterns, comprising 5, 2, 1 and 1 isolates respectively. Spa-typing of the 27 strains, allocated 26 into spa type t044, a type closely associated with the ST80 clone and one to spa type t131 which is also associated with the ST80 clone (Table).

\section{Discussion}

MRSA has become a significant cause of community-acquired skin and soft-tissue infections in many parts of the world $[12,13]$. The worldwide spread of PVL-positive CA-MRSA clones that were initially described at the beginning of this decade to be continent specific [12] has been documented [12]. Furthermore, new lineages of PVL-positive CA-MRSA strains have also been detected [13].

It is well recognised that the high prevalence of MRSA among S. aureus skin and soft-tissue infections observed in the USA, is due to the spread of a single clone that can be identified on the basis of PFGE and other genotyping characteristics. This clone, a result of recent clonal expansion and diversification of a subset of isolates [14] is designated as the USA300 clone by the United States Centres for Disease Control and Prevention (CDC) in Atlanta. It belongs to MLST (ST8) and spa type (t008) which are different from the ones described in this study $[15,16]$

In Europe although CA-MRSA skin and soft-tissue infections have been reported from most countries, the prevalence of infections due to CA-MRSA appear to vary across the continent [17-27]. However, reports of prevalence rates of MRSA among $S$. aureus infections are, to the best of our knowledge, lacking. The currently prevailing genetic type among CA-MRSA in Europe is the PVL-positive, t044/ ST80-SCCmec type IV [12]. In a recent Danish study, travel to or residing in countries abroad, especially in the Mediterranean region, the Balkans (Serbia) and the Middle East, where there is a high prevalence of CA-MRSA infections caused by t044/ST80SCCmec type IV, have been associated with infections with this type
[17]. Moreover, in some European countries strains with USA300 genotype are starting to be isolated with increasing frequency: The emergence of clones that are related to the USA300 has been associated with increasing rates of CA-MRSA in Spain. These clones were primarily isolated from immigrants from South America [25]. Further increasing isolation rates of the USA300 clone have been reported in Germany [26].

Contrary to the high degree of molecular diversity among CAMRSA that has been shown in various parts of Europe [17, 24, 27], our study documented high genetic relatedness among the PVL-positive CA-MRSA isolates, which might indicate a successful and rapid spread of this clone in Greece. The study has some limitations since it focuses on patients presenting at the outpatient department of a large hospital, a fact that might be a selective factor for more serious infections. Nevertheless, the high prevalence of PVL-positive CA-MRSA has implications for both antimicrobial

\section{T A B L E}

Main characteristics of community-acquired methicillinresistant Staphylococcus aureus (CA-MRSA) strains* isolated in a tertiary-care hospital in Athens, Greece, January 2006 December $2007(n=27)$

\begin{tabular}{|c|c|c|c|c|c|c|}
\hline No & Sex** & Age & Disease & $\begin{array}{l}\text { PFGE } \\
\text { type }\end{array}$ & $\begin{array}{c}\text { spa } \\
\text { type }\end{array}$ & $\begin{array}{l}\text { Resistance } \\
\text { Phenotype*** }\end{array}$ \\
\hline 1 & M & 45 & Furuncle & A1 & t044 & Oxa Tet Km FA \\
\hline 2 & M & 43 & Abscess (skin) & A & t044 & Oxa Tet Km FA \\
\hline 3 & $\mathrm{~F}$ & 45 & Abscess (skin) & A & t044 & Oxa Tet Km FA \\
\hline 4 & M & 34 & Furuncle & A1 & t044 & Oxa Tet Km FA \\
\hline 5 & $\mathrm{~F}$ & 43 & Abscess (soft tissue) & A & t044 & Oxa Tet Km FA \\
\hline 6 & $\mathrm{~F}$ & 46 & Folliculitis & A & $\mathrm{t} 131$ & Oxa Tet Km FA \\
\hline 7 & M & 51 & Furuncle & A2 & t044 & Oxa Tet $\mathrm{Km} \mathrm{FA}$ \\
\hline 8 & $\mathrm{~F}$ & 32 & Abscess (soft tissue) & A & t044 & Oxa Tet Km FA \\
\hline 9 & M & 45 & Abscess (soft tissue) & A & t044 & Oxa Tet $\mathrm{Km} \mathrm{FA}$ \\
\hline 10 & M & 32 & Abscess (soft tissue) & A & t044 & Oxa Tet Km FA \\
\hline 11 & $\mathrm{~F}$ & 38 & Abscess (skin) & A & t044 & Oxa Tet Km FA \\
\hline 12 & $\mathrm{~F}$ & 31 & Wound infection & $\mathrm{A} 1$ & t044 & Oxa Tet Km FA \\
\hline 13 & $\mathrm{~F}$ & 29 & Abscess (skin) & A & t044 & Oxa Tet Km FA \\
\hline 14 & M & 35 & Wound infection & A & t044 & Oxa Tet Km FA \\
\hline 15 & $\mathrm{~F}$ & 48 & Furuncle & A & t044 & Oxa Tet $\mathrm{Km} \mathrm{FA}$ \\
\hline 16 & M & 39 & Abscess (skin) & A3 & t044 & Oxa Tet Km FA \\
\hline 17 & $\mathrm{~F}$ & 46 & Abscess (skin) & A & t044 & Oxa Tet Km FA \\
\hline 18 & M & 51 & Abscess (soft tissue) & $\mathrm{A} 2$ & t044 & Oxa Tet Km FA \\
\hline 19 & M & 56 & Abscess (soft tissue) & $\mathrm{A} 1$ & t044 & Oxa Tet Km FA \\
\hline 20 & $\mathrm{~F}$ & 51 & Furuncle & A & t044 & Oxa Tet Km FA \\
\hline 21 & M & 45 & Abscess (soft tissue) & A & t044 & Oxa Tet Km FA \\
\hline 22 & M & 47 & Abscess (soft tissue) & A & t044 & Oxa Tet Km FA \\
\hline 23 & M & 43 & Wound infection & A & t044 & Oxa Tet Km FA \\
\hline 24 & $\mathrm{~F}$ & 46 & Abscess (soft tissue) & A & t044 & Oxa Tet Km FA \\
\hline 25 & $\mathrm{~F}$ & 51 & Wound infection & A4 & t044 & Oxa Tet Km FA \\
\hline 26 & M & 34 & Furuncle & A & t044 & Oxa Tet Km FA \\
\hline 27 & $\mathrm{~F}$ & 51 & Abscess (skin) & A1 & t044 & Oxa Tet $\mathrm{Km} \mathrm{FA}$ \\
\hline
\end{tabular}

* Note: All stains were sensitive to tobramycin and gentamicin,

cotrimoxazole, chloramphenicol, quinolones, clindamycin, erythromycin. ** $M=$ male; $F=$ female

*** Oxa=0xacyclin; Tet=Tetracyclin; $\mathrm{Km}=$ Kanamycin; FA=Fucidic acid 
treatment and MRSA surveillance in Greece. Our results indicate that in this country empiric therapy when clinically indicated, should exclude $\beta$-lactam antibiotics. Moreover, empiric use of macrolides for purulent skin and soft-tissue infections should be monitored closely. Clindamycin, trimethoprim-sulfamethoxazole, or linezolid, because of their good activities against all $S$. aureus in general, are potential alternatives to $\beta$-lactams for oral application. However, routine microbiologic workup should be performed for all community-acquired skin and soft-tissue infections in this country.

In contrast to the well documented nosocomial spread of CAMRSA in the USA, outbreaks of nosocomial infections due to CAMRSA have so far been reported only sparsely in Europe, with eight cases in Germany in 2005 [28]. This might be due to an overall low prevalence of CA-MRSA in the European population, and thus a rare introduction of such strains to the hospitals by admission of colonised carriers on the one hand. On the other, the high clinical manifestation index of CA-MRSA might lead to an earlier detection of patients infected with CA-MRSA. The phenomenon may also indicate that ST80-MRSA type IV isolates are less well adapted to be sustained in hospital environments [17]. However, in Greece, PVL-positive ST80-MRSA type IV CA-MRSA have been introduced in at least one hospital since 2000 [29, 30], a fact of great public health significance. These strains are associated with increased disease severity mainly due to the presence of PVL genes, and a possible adaptation in the hospital environment would result in outbreaks of serious nosocomial infections. This perspective is of immense importance in a country already suffering from high rates of infections due to multidrug-resistant organisms (see Greek System for the Surveillance of Antimicrobial Resistance www. medne.gr/whonet and ERASS http://www.rivm.nl/earss/).

In conclusion we believe that the establishment of an active screening programme for PVL-positive CA-MRSA carriage and adopting a search and destroy strategy for CA-MRSA in all patients admitted with purulent skin and soft-tissue is of high priority Greece as well as in all European counties who face high rates of CA-MRSA infections.

\section{Aknowledgements}

Strain CA-MRSA 3925/02 (ST80) is a generous gift from Professor W Witte.

The Greek System for the Surveillance of Antimicrobial Resistance is sponsored by the Hellenic Centre for Infectious Disease Control (KEELPNO), Ministry of Health

\section{References}

1. Weber JT. Community-associated methicillin-resistant Staphylococcus aureus. Clin Infect Dis. 2005;41(Suppl 4):S269-72.

2. Maltezou HC, Giamarellou H. Community-acquired methicillin-resistant Staphylococcus aureus infections. Int J Antimicrob Agents. 2006; 27(2):87-96.

3. Centers for Disease Control and Prevention. Four pediatric deaths from community-acquired methicillin-resistant Staphylococcus aureus -Minnesota and North Dakota, 1997-1999. Morb Mortal Wkly Rep. 1999;48:707-10.

4. Gillet Y, Issartel B, Vanhems P, Fournet JC, Lina G, Bes M, et al. Association between Staphylococcus aureus strains carrying gene for Panton-Valentine leukocidin and highly lethal necrotising pneumonia in young immunocompetent patients. Lancet. 2002; 359(9308):753-9.
5. Vourli S, Perimeni D, Makri A, Polemis M, Voyiatzi A, Vatopoulos A. Community acquired MRSA infections in a paediatric population in Greece. Euro Surveill. 2005;10(5):pij=537. Available from: http://www.eurosurveillance.org/ViewArticle. aspx?ArticleId $=537$

6. Niniou I, Vourli S, Lebessi E, Foustoukou M, Vatopoulos A, Pasparakis DG, et al. Clinical and molecular epidemiology of community-acquired, methicillinresistant Staphylococcus aureus infections in children in central Greece. Eur J Clin Microbiol Infect Dis. 2008;27(9):831-7.

7. Clinical and Laboratory Standards Institute. Performance Standards for Antimicrobial Susceptibility Testing; Seventeenth Informational Supplement: Approved Standard M100-S17. Wayne, Pennsylvania (USA): Clinical and Laboratory Standards Institute. 2007

8. Oliveira DC, de Lencastre H. Multiplex PCR strategy for rapid identification of structural types and variants of the mec element in methicillin-resistant Staphylococcus aureus. Antimicrob Agents Chemother. 2002;46(7):2155-61.

9. Lina G, Piémont Y, Godail-Gamot F, Bes M, Peter MO, Gauduchon V, et al. Involvement of Panton-Valentine leukocidin-producing Staphylococcus aureus inprimary skin infections and pneumonia.Clin Infect Dis. 1999;29(5):1128-32.

10. Murchan S, Kaufmann ME, Deplano A, de Ryck R, Struelens M, Elsberg Zinn $\mathrm{CE}$, et al. Harmonization of pulsed-field gel electrophoresis protocols for epidemiological typing of strains of methicillin-resistant Staphylococus aureus: a single approach developed by consensus in 10 European laboratories and its application for tracing the spread of related strains. J Clin Microbiol. 2003;41(4): 1574-85.

11. Harmsen D, Claus H, Witte W, Rothgänger J, Claus H, Turnwald D, et al . Typing of methicillin-resistant Staphylococcus aureus in a university hospital setting by using novel software for spa repeat determination and database management. J Clin Microbiol. 2003;41(12):5442-8.

12. Tristan A, Bes M, Meugnier H, Lina G, Bozdogan B, Courvalin P, et al. Global distribution of Panton-Valentine leukocidin-positive methicillin-resistant Staphylococcus aureus, 2006. Emerg Infect Dis. 2007;13(4):594-600.

13. Vandenesch F, Naimi T, Enright MC, Lina G, Nimmo GR, Heffernan H, et al. Community-acquired methicillin-resistant Staphylococcus aureus carrying Panton-Valentine leukocidin genes: worldwide emergence. Emerg Infect Dis. 2003;9(8):978-84.

14. Kennedy AD, Otto M, Braughton KR, Whitney AR, Chen L, Mathema B, et al. Epidemic community-associated methicillin-resistant Staphylococcus aureus: recent clonal expansion and diversification. Proc Natl Acad Sci U S A. 2008;105(4):1327-32.

15. Moran GJ, Krishnadasan A, Gorwitz RJ, Fosheim GE, McDougal LK, Carey RB, et al. Methicillin-resistant Staphylococcus aureus infections among patients in the emergency department. N Engl J Med 2006;355(7):666-74.

16. King MD, Humphrey BJ, Wang YF, Kourbatova EV, Ray SM, Blumberg HM. Emergence of community-acquired methicillin-resistant Staphylococcus aureus USA 300 clone as the predominant cause of skin and soft-tissue infections. Ann Intern Med 2006;144(5):309-317.

17. Larsen AR, Böcher S, Stegger M, Goering R, Pallesen LV, Skov R. Epidemiology of European community-associated methicillin-resistant Staphylococcus aureus clonal complex 80 type IV strains isolated in Denmark from 1993 to 2004. J Clin Microbiol. 2008;46(1):62-8.

18. Loughrey A, Millar BC, Goldsmith CE, Rooney PJ, Moore JE. Emergence of community-associated MRSA (CA-MRSA) in Northern Ireland. Ulster Med J. 2007;76(2):68-71.

19. Baranovich T, Yamamoto T, Potapov V. The first isolation of PantonValentine leukocidin (PVL) positive community-acquired methicillinresistant Staphylococcus aureus (CA-MRSA) in Russia. Euro Surveill. 2007;12(11):pii=3157. Available from: http://www.eurosurveillance.org/ ViewArticle.aspx?ArticleId $=3157$

20. Adedeji A, Weller TM, Gray JW. MRSA in children presenting to hospitals in Birmingham, UK. J Hosp Infect. 2007;65(1):29-34.

21. Grmek Kosnik I, Kraigher A, Hocevar-Grom A, Perpar Veninšek I. Monitoring CA-MRSA infections in Slovenia. Euro Surveill. 2005;10(37):pii=2793. Available from: http://www.eurosurveillance.org/ViewArticle.aspx?ArticleId=2793

22. Aramburu C, Harbarth S, Liassine N, Girard M, Gervaix A, Scherenzel J, Renzi G, Sudre P. Community-acquired methicillin-resistant Staphylococcus aureus in Switzerland : first surveillance report. Euro Surveill. 2006;11(1):pij=594. Available from: http://www.eurosurveillance.org/ViewArticle. aspx?ArticleId $=594$

23. Naas T, Fortineau N, Spicq C, Robert J, Jarlier V, Nordmann P. Three-year survey of community-acquired methicillin-resistant Staphylococcus aureus producing Panton-Valentine leukocidin in a French university hospital. J Hosp Infect. 2005;61(4):321-9.

24. Krziwanek K, Luger C, Sammer B, Stumvoll S, Stammler M, Metz-Gercek $\mathrm{S}$, et al. PVL-positive MRSA in Austria. Eur J Clin Microbiol Infect Dis. 2007;26(12):931-5. 
25. Manzur A, Dominguez AM, Pujol M, González MP, Limon E, Hornero A, et al. Community-acquired methicillin-resistant Staphylococcus aureus infections: an emerging threat in Spain. Clin Microbiol Infect. 2008;14(4):377-80.

26. Witte W, Strommenger B, Cuny C, Heuck D, Nuebel U. Methicillin-resistant Staphylococcus aureus containing the Panton-Valentine leucocidin gene in Germany in 2005 and 2006. J Antimicrob Chemother. 2007;60(6):1258-63.

27. Holmes A, Ganner M, McGuane S, Pitt TL, Cookson BD, Kearns AM. Staphylococcus aureus isolates carrying Panton-Valentine leucocidin genes in England and Wales: frequency, characterization, and association with clinical disease. $J$ Clin Microbiol. 2005;43(5):2384-90.

28. Linde H, Wagenlehner F, Strommenger B, Drubel I, Tanzer J, Reischl U, et al. Healthcare-associated outbreaks and community-acquired infections due to MRSA carrying the Panton-Valentine leucocidin gene in southeastern Germany. Eur J Clin Microbiol Infect Dis. 2005;24(6):419-422.

29. Aires de Sousa M, Bartzavali C, Spiliopoulou I, Santos Sanches I, Crisostomo MI, de Lencastre H. Two international methicillin-resistant Staphylococcus aureus clones endemic in a university hospital in Patras, Greece. J Clin Microbiol. 2003;41(5):2027-32.

30. Chini V, Petinaki E, Foka A, Paratiras S, Dimitracopoulos G, Spiliopoulou I Spread of Staphylococcus aureus clinical isolates carrying Panton-Valentine leukocidin genes during a 3-year period in Greece. Clin Microbiol Infect. 2006;12(1):29-34.

This article was published on 15 January 2009.

Citation style for this article: Vourli S, Vagiakou H, Ganteris G, Orfanidou M, Polemis M, Vatopoulos A, Malamou-Ladas H. High rates of community-acquired, Panton-Valentine leukocidin (PVL)- positive methicillin-resistant S. aureus (MRSA) infections in adult outpatients in Greece. Euro Surveill. 2009;14(2):pii=19089. Available online: http://www. eurosurveillance.org/ViewArticle.aspx?ArticleId $=19089$ 